\title{
The Complement System: A Prey of Trypanosoma cruzi
}

Kárita C. F. Lidani * , Lorena Bavia ${ }^{\dagger}$, Altair R. Ambrosio' ${ }^{\dagger}$ and lara J. de Messias-Reason*

Laboratory of Molecular Immunopathology, Clinical Hospital, Federal University of Paraná, Curitiba, Brazil

Trypanosoma cruzi is a protozoan parasite known to cause Chagas disease (CD), a neglected sickness that affects around 6-8 million people worldwide. Originally, CD was mainly found in Latin America but more recently, it has been spread to countries in North America, Asia, and Europe due the international migration from endemic areas. Thus, at present CD represents an important concern of global public health. Most of individuals that are infected by $T$. cruzi may remain in asymptomatic form all lifelong, but up to $40 \%$ of them will develop cardiomyopathy, digestive mega syndromes, or both. The interaction between the T. cruzi infective forms and host-related immune factors represents a key point for a better understanding of the physiopathology of CD. In this context, the complement, as one of the first line of host defense against infection was shown to play an important role in recognizing T. cruzi metacyclic trypomastigotes and in controlling parasite invasion. The complement consists of at least 35 or more plasma proteins and cell surface receptors/regulators, which can be activated by three pathways: classical $(C P)$, lectin $(\mathrm{LP})$, and alternative (AP). The CP and LP are mainly initiated by immune complexes or pathogen-associated molecular patterns (PAMPs), respectively, whereas AP is spontaneously activated by hydrolysis of C3. Once activated, several relevant complement functions are generated which include opsonization and phagocytosis of particles or microorganisms and cell lysis. An important step during T. cruzi infection is when intracellular trypomastigotes are release to bloodstream where they may be target by complement. Nevertheless, the parasite uses a sequence of events in order to escape from complement-mediated lysis. In fact, several T. cruzi molecules are known to interfere in the initiation of all three pathways and in the assembly of C3 convertase, a key step in the activation of complement. Moreover, T. cruzi promotes secretion of plasma membrane-derived vesicles from host cells, which prevent the activity of $\mathrm{C} 3$ convertase $\mathrm{C} 4 \mathrm{~b} 2 \mathrm{a}$ and thereby may hinder complement. In this review, we aim to present an overview on the strategies used by T. cruzi in order to circumvent the activation of complement and, consequently, its biological effects.

\footnotetext{
Keywords: Trypanosoma cruzi, complement system, complement regulatory proteins, evasion mechanism, innate immunity
}

\section{INTRODUCTION}

Trypanosoma cruzi is a hemoflagellate parasite of the order Kinetoplastida and Trypanosomatidae family (Levine et al., 1980) that causes CD. The parasite presents complex mechanisms of surveillance in the mammalian host and exerts direct influence on the course of CD (Watanabe Costa et al., 2016). CD is responsible for more expressive morbimortality than any other parasitic 
disease (World Health Organization [WHO], 2010; Bonney, 2014 ), resulting in a global annual burden of $\$ 627.5$ million in health-care costs (Lee et al., 2013). It is estimated that 6-8 million people are infected with T. cruzi from 21 countries in Latin America (Stanaway and Roth, 2015), where 25 million people live at risk of acquiring the disease (Pereira and Navarro, 2013; World Health Organization [WHO], 2015). Furthermore, owing to the widespread human migration from $\mathrm{CD}$-endemic areas, the disease has become an emerging global health concern, affecting several countries in Europe (World Health Organization [WHO], 2009; Navarro et al., 2012; European Centre for Disease Prevention and Control [ECDC], 2014), the United States (Bern and Montgomery, 2009), and Japan (Schmunis, 2007), where transmission occurs mainly through blood transfusions, organ transplants, or by congenital routes (Singh and Sehgal, 2010).

Although most of $T$. cruzi-infected people remain asymptomatic throughout their lives, the parasite-host interaction seems to be crucial for the development of the disease and the severity of the chronic symptomatic forms. In this context, the complement system plays an important role as a first line of host immune defense promoting the recognition, opsonization, and direct lysis of invading pathogens. However, during T. cruzi infection in humans, the activation of complement may present a dual role in both the acute and chronic phases of $\mathrm{CD}$, initially being crucial in controlling the parasitemia, but later in the chronic phase contributing to the development or severity of the symptomatic forms because of its proinflammatory effect (Boldt et al., 2011; Weitzel et al., 2012; Luz et al., 2013, 2016). Considering that activation of complement by the lectin, classical, and APs leads to a proteolytic cascade and ultimately to a powerful lytic effect, this system is a special target for evasion strategies used by microbes in order to ensure infection success and possibly progression to chronic disease (Lambris et al., 2008). In fact, $T$. cruzi displays a range of different strategies to circumvent the harmful effects of the complement proteolytic cascade, which enables the parasite's survival and development of $\mathrm{CD}$. Therefore, we review here published information on T. cruzi-derived proteins that are involved in complement evasion which are critical to successful infection and disease progression.

\footnotetext{
Abbreviations: AP, alternative pathway; C1-INH, C1 esterase inhibitor; $\mathrm{C} 1 \mathrm{qR}$, $\mathrm{C} 1 \mathrm{q}$ receptor; $\mathrm{C} 4 \mathrm{BP}$, $\mathrm{C} 4 \mathrm{~b}$-binding protein; $\mathrm{CD}$, chagas disease; $\mathrm{CD} 46$, membrane cofactor protein; CD59, inhibitor membrane attack complex-inhibitory protein; CP, classical pathway; CL-K1, collectin -11; CRIT, complement C2 receptor inhibitor trispanning; CR1, complement receptor 1; DAF, decay accelerating factor or CD55; ELISA, enzyme-linked immunosorbent assay; ER, endoplasmic reticulum; FB, factor B; FD, factor D; GlaNAc, $N$-acetylgalactosamine; GlcNAc, $\mathrm{N}$-acetyl-D-glucosamine; HuCRT, human calreticulin; IFA, immunofluorescence antibody test; LP, lectin pathway; MAC, membrane attack complex; MASP-1, MBLassociated serine proteases - 1; MASP-2, MBL-associated serine proteases - 2; MBL, mannose-binding lectin; MV, microvesicles; NHS, normal human serum; PAMPs, pathogen-associated molecular patterns; PCR, polymerase chain reaction; PRMs, pattern-recognition molecules; Sh-TOR, Schistosoma haematobium; T. cruzi, Trypanosoma cruzi; TcCRT, Trypanosoma cruzi calreticulin; TcCRIT, Trypanosoma cruzi complement C2 receptor inhibitor trispanning; TcCRP, Trypanosoma cruzi complement regulatory protein or Gp160; T-DAF, trypomastigote decayaccelerating factor; TOR, trispanning orphan receptor.
}

\section{Trypanosoma cruzi AND CHAGAS DISEASE}

\section{T. cruzi Life Cycle}

Trypanosoma cruzi infection occurs predominantly via vectorial transmission by triatomine bugs of the genera Triatoma, Rhodnius, and Panstrongylus. These bugs suck the blood of vertebrates infected with trypomastigotes, and this initiates the parasite life cycle. Once ingested by the insect vector, trypomastigotes are transformed in the anterior midgut either into spheromastigote or epimastigote forms. Epimastigotes multiply in the midgut and attach to the perimicrovillar membranes of the triatomine intestinal cells. At the most posterior region of the vector's intestine and at the rectum, many epimastigotes detach from the intestinal surface and become infective metacyclic trypomastigotes, which are then released with feces and urine during blood meals. However, metacyclic trypomastigotes are not able to penetrate the intact host skin and enter through the rubbing or scratching of the bite wound, or through permissive mucosal or conjunctival surfaces at the inoculation site. Recruitment and fusion of the host lysosome with the parasite involves the formation of a parasitophorous endocytic vacuole, which is needed for parasite invasion of fibroblasts, macrophages, and epithelial cells (Souza et al., 2010; Nogueira et al., 2015). Subsequently, the parasite promotes enzymatic lysis of the vacuole membrane, differentiating into intracellular amastigotes, which after nine cycles of binary division become trypomastigotes that are eventually released into the circulation as bloodstream trypomastigotes (Dvorak and Hyde, 1973; Dvorak and Howe, 1976). These either infect new cells or are taken up by a new insect vector during a blood meal, repeating the parasite cycle.

Once in the bloodstream of a mammalian host, T. cruzi is able to infect several cell types from a variety of tissues thereby spreading to new infection sites where they differentiate into intracellular amastigotes (Watanabe Costa et al., 2016) (Figure 1). Besides vectorial transmission, T. cruzi can also be transmitted through blood transfusion, organ transplantation, transplacentally, the ingestion of contaminated food or drinks, or by accidental exposure; however, the physiopathological mechanisms of such transmissions are still unclear.

\section{Chagas Disease}

Several clinical manifestations may result in humans from T. cruzi infection. This initiates with an acute phase that last for about 2 months characterized by high parasitemia. In this stage, the diagnosis may be achieved by direct visualization of the parasite in blood and by the detection of $\operatorname{IgG}$ antibodies against $T$. cruzi antigens. Although most acute cases are oligosymptomatic or asymptomatic, initial dermatologic manifestations resulting in a skin lesion (chagoma), eyelid edema and conjunctivitis (Romaña sign), or generalized morbilliform eruption (schizotrypanides) may be present (Nunes et al., 2013). Other symptoms may include anorexia, fever, headache, dyspnea, abdominal pain, cough, hepatosplenomegaly, rash, 


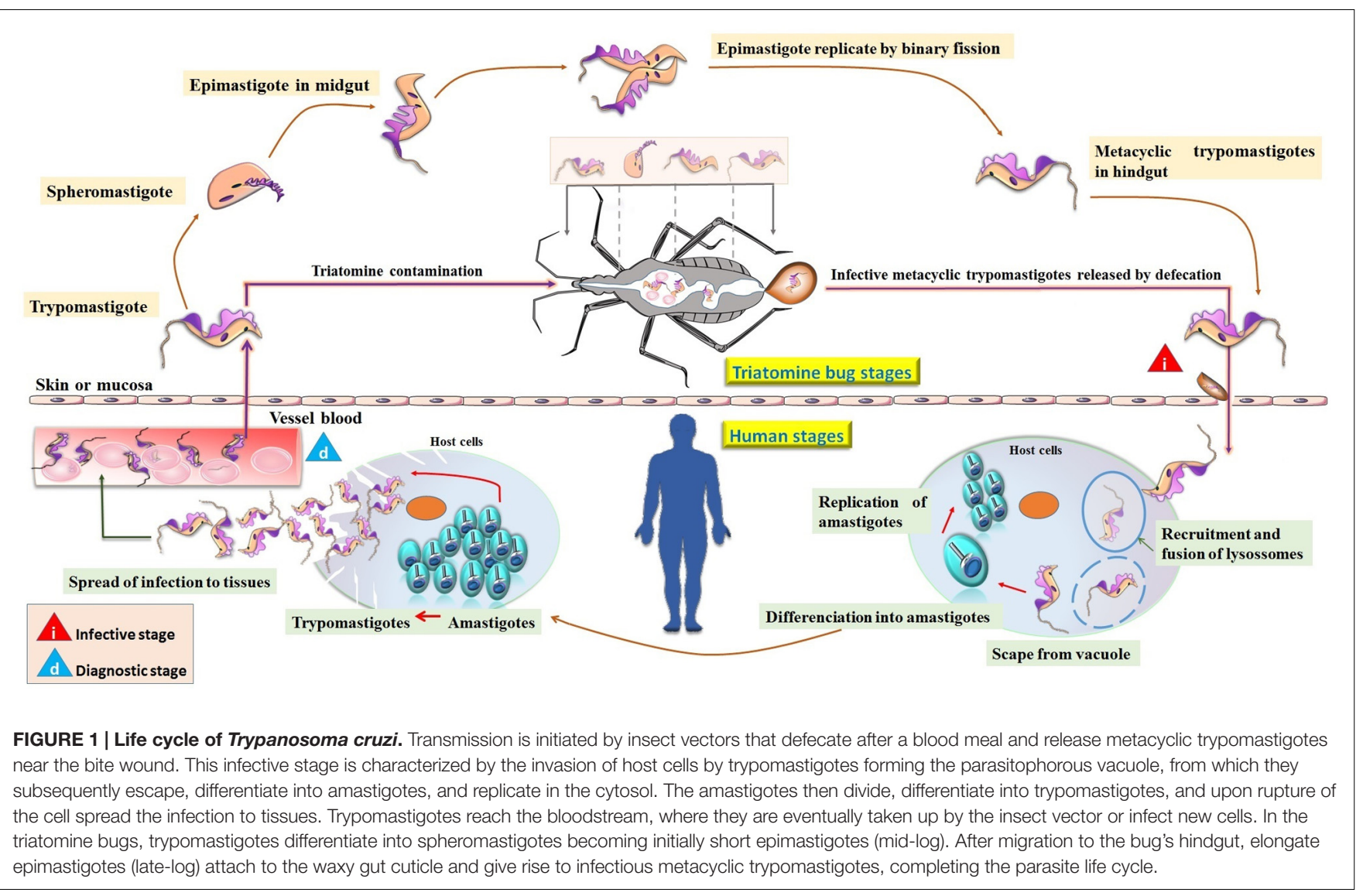

painful nodules, generalized body swelling, and myocarditis (Hidron et al., 2010; Malik et al., 2015).

Following the acute phase, most infected people enter into a prolonged asymptomatic indeterminate form of the chronic disease and will never develop Chagas-related symptoms. However, after 10-30 years of infection approximately $30-40 \%$ of chronically infected people will present some clinical manifestations such as cardiomyopathy (20-30\%), digestive commitment (10-15\%) or both (1-5\%) (Rassi and Marin-Neto, 2010). Chronic cardiomyopathy represents the most severe and life-threatening manifestation of human $\mathrm{CD}$, ranging from asymptomatic electrocardiogram abnormalities to congestive heart failure, arrhythmias, and/or thromboembolic events (Biolo et al., 2010) that are associated with high morbidity and mortality. In fact, mortality related with $\mathrm{CD}$ is generally due to cardiovascular involvement, with approximately 12,000 deaths every year (Salvatella et al., 2013), with sudden death accounting for around $60 \%$, heart failure $25-30 \%$ and stroke $10-15 \%$ (Rassi et al., 2001).

Standard approaches for CD diagnosis in the chronic phase require at least two different serological tests, generally using ELISA and IFA (Bern et al., 2007). Additionally, amplification of parasite DNA by PCR may be employed in some uncertain cases (Schijman et al., 2011) (Figure 2).

\section{THE COMPLEMENT SYSTEM}

The complement system constitutes a key component of innate immunity with a significant role in the first line of defense against invading microbes. It comprises more than 35 plasma and cell membrane receptor/regulator proteins that become activated mainly by three pathways: lectin (LP), classical (CP), and alternative (AP), resulting in important biological responses such as inflammation, phagocytosis, and lysis of pathogens (Ricklin et al., 2010). Activation of complement and its potent inflammatory response through the production of molecules with anaphylatoxin activity was first demonstrated by Dias da Silva and Lepow (1967). The functional role in vascular permeability, histamine release from mast cells and contraction of smooth muscle of the anaphylatoxins (C4a, C3a, and C5a) was subsequently reported (Dias da Silva and Lepow, 1967; Dias da Silva et al., 1967; Cochrane and Müller-Eberhard, 1968). Besides inflammatory response, the complement also plays an important role in the solubilization and removal of circulating immune complexes to avoid their deposition, which could result in tissue injury (Miller and Nussenzweig, 1974). In addition, the complement system links the innate and acquired responses through the activation of B lymphocytes and synthesis of immunoglobulins (Walport, 2001; Ricklin et al., 2010, 2016). Furthermore, complement is involved in the opsonization of 


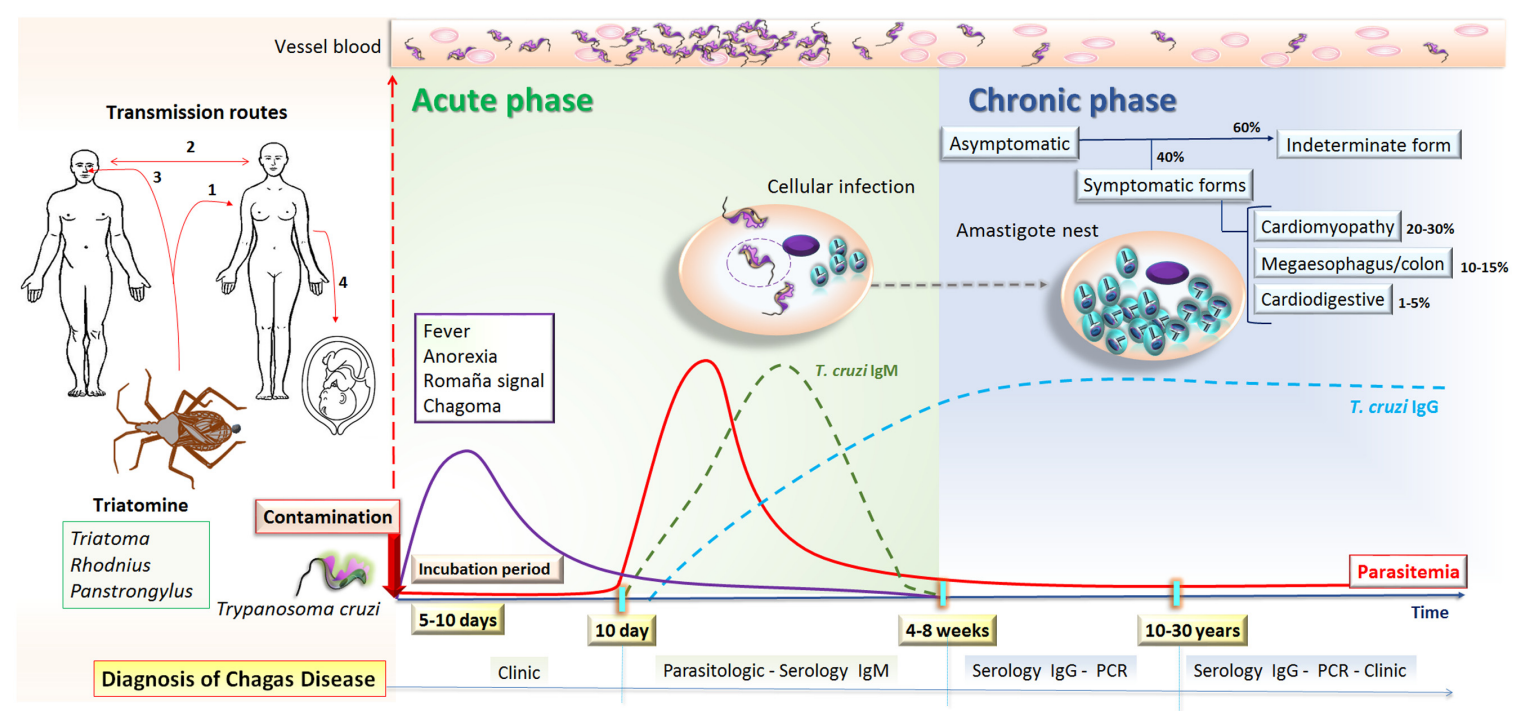

FIGURE 2 | Natural course of human $\boldsymbol{T}$. cruzi infection. T. cruzi transmission can occur by (1) vectorial (2) blood transfusion or organ transplantation, (3) oral, or (4) congenital routes. The incubation period lasts for 5-10 days after human contamination with T. cruzi from triatomines, which is followed by the acute phase of Chagas disease that lasts $4-8$ weeks. This phase is characterized by circulating trypomastigotes, which can be visualized in the blood and IgM anti-T. cruzi antibodies can be detected after 10 days of infection. Most patients have non-specific symptoms, such as fever and anorexia, or are asymptomatic, and may develop inflammation and swelling at the site of inoculation in the skin or conjunctiva, characterizing chagoma and Romaña's signal, respectively. The chronic phase begins once parasitemia falls below detectable levels by microscopy, usually 4 to 8 weeks after the onset of infection, and therefore diagnosis is based on the detection of anti-T. cruzi lgG antibodies or molecular tests. In this phase, most infected people enter a prolonged asymptomatic form known as the indeterminate form and will never develop Chagas-related symptoms. However, after 10-30 years around 30-40\% of chronically infected people will present some clinical manifestations including cardiac, digestive, or cardiodigestive complaints.

apoptotic cells contributing to their phagocytosis and removal from circulation (Flierman and Daha, 2007).

Complement is activated mainly by three pathways, LP, CP, and AP, which lead to the generation of effector molecules, selfamplification, and the induction of immune signaling (Ricklin et al., 2010). The LP can be triggered through the binding of PRMs, such as MBL, ficolins (Ficolin-1 [or M-ficolin], Ficolin-2 [or L-ficolin], and Ficolin-3 [or H-ficolin]) and CL$\mathrm{K} 1$, to PAMPs on the pathogen's surface (Beltrame et al., 2015). Whereas carbohydrate-recognition domains in the MBL molecule bind to sugar moieties on the pathogen's surface (such as D-mannose, glucose, L-fucose, and GlcNAc) (Weis et al., 1992), the three human ficolins bind to PAMPs by fibrinogen-like recognition domains and exhibit differences in their binding specificities (Gout et al., 2010). For instances, Ficolin-1 recognizes $N$-acetylated compounds (such as GlcNAc and $N$-acetylgalactosamine [GalNAc]) (Frederiksen et al., 2005), $\mathrm{O}$-acetylated and glycan compounds containing sialic acid (Gout et al., 2010). Ficolin-2 also recognizes $N$-acetylated compounds and capsulated strains of bacteria (Frederiksen et al., 2005; Gout et al., 2010), while Ficolin-3 binds GalNAc, GlcNAc, D-fucose as mono/oligosaccharides and lipopolysaccharides (Sugimoto et al., 1998). In addition, CL-K1 senses mannose and fucose-containing microbial derived products (Keshi et al., 2006). Following the binding of MBL, ficolins, or CL-K1 to PAMPs, the LP is initiated by the activation of MASP-1 and MASP-2 resulting in active forms (Kjaer et al., 2013) that cleave C4 in C4a and C4b, and C2 in $\mathrm{C} 2 \mathrm{a}$ and $\mathrm{C} 2 \mathrm{~b}$, culminating with the formation of the LP C3 convertase (C4b2a) and C5 convertase (C4bC2aC3b) (Walport, 2001; Ricklin et al., 2010; Merle et al., 2015).

The activation of the CP depends mainly on the interaction of C1 with antigen-antibody complexes or alternatively, by PAMPs (lipopolysaccharides and porins from Gram-negative bacteria), phospholipids, apoptotic cells (phosphatidylserine) or pentraxins (C-reactive protein and pentraxin 3), among others (Alberti et al., 1993; Kishore et al., 2004). The C1 complex is formed of one C1q molecule and two molecules each of $\mathrm{C} 1 \mathrm{r}$ and $\mathrm{C} 1 \mathrm{~s}$ (C1qC1r2C1s2). $\mathrm{C} 1 \mathrm{q}$ initiates the activation of the $\mathrm{CP}$ by binding to $\mathrm{CH} 3$ or $\mathrm{CH} 2 \mathrm{Fc}$ domains of $\operatorname{IgM}$ and $\operatorname{IgG}$, respectively, inducing a conformational change in C1q. This leads to the activation of $\mathrm{C} 1 \mathrm{r}$ and $\mathrm{C} 1 \mathrm{~s}$, and serine proteases that cleave C4 and C2 (Lörincz et al., 2000), forming the CP C3 and C5 convertases (C4b2a and $\mathrm{C} 4 \mathrm{bC} 2 \mathrm{aC} 3 \mathrm{~b}$ ), similar to those generated in the LP (Ricklin et al., 2010).

The activation of the AP starts with spontaneous hydrolysis of the thiol-ester bond in $\mathrm{C} 3 \alpha$-chain generating $\mathrm{C} 3(\mathrm{H} 2 \mathrm{O})$. This molecule exhibits a reactive site for the plasma protein $\mathrm{FB}$, forming the complex $\mathrm{C} 3(\mathrm{H} 2 \mathrm{O}) \mathrm{B}$. In this condition, $\mathrm{FB}$ can be cleaved by $\mathrm{FD}$ in $\mathrm{Ba}$ and $\mathrm{Bb}$. The $\mathrm{Bb}$ fragment remains bound to $\mathrm{C} 3(\mathrm{H} 2 \mathrm{O})$, forming the first $\mathrm{C} 3$ convertase of $\mathrm{AP}(\mathrm{C} 3(\mathrm{H} 2 \mathrm{O}) \mathrm{Bb})$, which now exhibits serine protease activity cleaving further $\mathrm{C} 3$ molecules into $\mathrm{C} 3 \mathrm{a}$ and $\mathrm{C} 3 \mathrm{~b}$. Like $\mathrm{C} 3(\mathrm{H} 2 \mathrm{O})$, C3b exhibits reactive sites for $\mathrm{FB}$ binding allowing its cleavage by $\mathrm{FD}$, resulting in the second $\mathrm{C} 3$ convertase of this pathway, C3bBb. Additionally, $\mathrm{C} 3$ binds to $\mathrm{C} 3 \mathrm{bBb}$ forming $\mathrm{C} 3 \mathrm{bBbC} 3 \mathrm{~b}$, a complex with $\mathrm{C} 5$ convertase activity (Walport, 2001; Ricklin et al., 2010). 
Once all three pathways are activated, the C5 convertases formed by both CP/LP (C4b2a3b) and AP (C3bBb3b) cleave C5 in $\mathrm{C} 5 \mathrm{a}$ and $\mathrm{C} 5 \mathrm{~b}$. The fragment $\mathrm{C} 5 \mathrm{~b}$ binds to $\mathrm{C} 6$, forming a stable complex $\mathrm{C} 5 \mathrm{~b} 6$, which recruits $\mathrm{C} 7$ resulting in a hydrophobic complex that targets cell membranes (mC5b-7). After C8 is incorporated to $\mathrm{mC} 5 \mathrm{~b}-7$, the $\mathrm{C} 5 \mathrm{~b} 678$ complex becomes inserted in the cell membrane. Then, 12-18 copies of the C9 molecule polymerize forming the MAC. This pore-forming ring structure (C5b678(9)n) gets inserted into the cell as a transmembrane channel, favoring ionic imbalance and an increase in intracellular volume leading to membrane cell disruption (Kondos et al., 2010).

Since undesirable activation of complement may lead to inflammation and tissue damage, an effective and accurate system of regulatory molecules is required for the maintenance of its homeostasis. In this context, a variety of membranebound inhibitory proteins (such as CR1, CD59, CD46, and DAF or CD55) downregulate local complement activation, protecting host cells from unwanted complement lysis (Carroll and Sim, 2011; Noris and Remuzzi, 2013). In addition, several plasma regulator proteins (such as Factor $\mathrm{H}$, Factor I, C1-INH, C4BP, and vitronectin) control soluble activated complement components and complexes (Carroll and Sim, 2011; Noris and Remuzzi, 2013). In general, either excessive or defective complement activation may be implicated in the pathogenesis of some conditions including autoimmune, chronic inflammatory, and infectious diseases (Ricklin and Lambris, 2013).

\section{Complement Activation by T. cruzi}

The interaction of complement with T. cruzi is a principal step in the immediate immune response of the host against the parasite. However, it is important to consider that this interaction is dependent on the evolutive forms of the parasite. Experimental studies showed that complement can be activated by amastigote (Iida et al., 1989), epimastigote (Nogueira et al., 1975), and trypomastigote forms (Kipnis et al., 1985), but only non-infective epimastigote forms are susceptible to complement lysis. However, some strains of metacyclic trypomastigotes have been shown to be susceptible to complement-mediated killing in vitro (Cestari and Ramirez, 2010). Epimastigotes can be recognize by MBL, ficolins, $\mathrm{C} 3$ and $\mathrm{C} 1 \mathrm{q}$, but $\mathrm{C} 3 \mathrm{~b}$ and $\mathrm{C} 4 \mathrm{~b}$ deposition assays revealed that complement activation occurred mainly by the LP and AP in non-immune sera (Cestari and Ramirez, 2010). CP can also be activated through the binding of specific antibodies to epimastigote's surface (Nogueira et al., 1975). As previously shown, AP can be activated by the spontaneous hydrolysis of $\mathrm{C} 3$; C3b is deposited on the epimastigote's surface supporting efficient formation of AP C3 convertase (Joiner et al., 1986). Since all pathways are activated and C3 convertases are formed, $\mathrm{C} 3$ is cleaved into $\mathrm{C} 3 \mathrm{a}$ and $\mathrm{C} 3 \mathrm{~b}$ with additional $\mathrm{C} 3 \mathrm{~b}$ molecules binding to $\mathrm{C} 3$ convertases, forming $\mathrm{C} 5$ convertases, which in turn cleave $\mathrm{C} 5$ into $\mathrm{C} 5 \mathrm{a}$ and $\mathrm{C} 5 \mathrm{~b}$. Then $\mathrm{C} 5 \mathrm{~b}$ recruits $\mathrm{C6}, \mathrm{C7}$, and C8 forming a C5b-8 complex where C9 molecules polymerize forming the MAC that induces the lysis of epimastigotes (Figure 3). Abrahamsohn and Dias da Silva (1977) demonstrated that epimastigotes treated with specific immune serum in the presence of splenic lymphocytes may be also killed in vitro by antibody dependent cell-mediated cytotoxicity.

During the differentiation cycle from non-infective/ complement susceptible to infective/complement resistance forms, trypomastigotes acquire the ability to circumvent complement lysis by TcCRT, TcCRP, TcCRIT, gp58/68, and T-DAF molecules. At the first stages of $T$. cruzi infection (seconds after infection), complement can be initially activated by the LP and AP since both pathways do not depend on a specific antibody response (Cestari et al., 2013). Thus, trypomastigotes can immediately be targeted by complement after accessing the host bloodstream. A wide range of carbohydrates (such as GalNAc and GlcNAc) anchored by glycosylphosphatidylinositol in the outer leaflet of T. cruzi plasma membrane (Lederkremer and Bertello, 2001; Buscaglia et al., 2006) can be recognized by PAMP sensor molecules, such as MBL and ficolins (Cestari et al., 2009; Cestari and Ramirez, 2010) leading to the activation of MASPs. Then, the serine protease MASP-2 cleaves C2 and C4 generating LP C3 convertase formation that activates C3 to form $\mathrm{C} 3 \mathrm{~b}$, contributing to the $\mathrm{AP}$ amplification loop with simultaneous LP and AP activation (Ricklin et al., 2010; Cestari et al., 2013). In addition, the activation of the AP can also take place spontaneously by hydrolysis of $\mathrm{C} 3$, which leads to the generation of C3 convertase and C3 cleavage. However, deposition of $\mathrm{C} 3 \mathrm{~b}$ on trypomastigotes may contribute to T. cruzi internalization by CR1 (van Lookeren et al., 2007). Both LP and AP can be continually activated, not only at the first stages of $T$. cruzi infection, but also during the course of chronic CD (Lidani et al., 2015). At a later stage of T. cruzi infection (days post-infection), CP becomes activated when antitrypomastigote-specific IgM and IgG antibodies are produced allowing $\mathrm{C} 1 \mathrm{q}$ binding and the activation of $\mathrm{C} 1 \mathrm{r}$ and $\mathrm{C} 1 \mathrm{~s}$ serine proteases that cleave $\mathrm{C} 4$ and $\mathrm{C} 2$ forming the CP C3 convertase. Although during T. cruzi infection complement is activated by these three pathways, the process is interrupted at the $\mathrm{C} 3$ convertase level by complement regulatory proteins derived from trypomastigotes that cause abrogation of the terminal pathway and MAC formation. This evasion from complement lysis allows trypomastigote cell invasion and tissue spreading driving the infection toward chronic disease.

\section{COMPLEMENT EVASION STRATEGIES USED BY T. cruzi}

The success of $T$. cruzi infection depends on a series of complex mechanisms that enable the parasite to evade the host immune response. In fact, $T$. cruzi employs a range of strategies to escape the effects of both innate and adaptive immunity. A crucial step occurs during the first seconds of infection when trypomastigotes needs to circumvent the harmful lytic attack of complement (Sacks and Sher, 2002). During differentiation from epimastigote to metacyclic trypomastigote forms inside the insect vector, the parasite undergoes a series of morphological and physiological changes that confers the capacity to evade the lytic effect of complement. The mechanism controlling this resistance mainly involves the expression of complement binding 


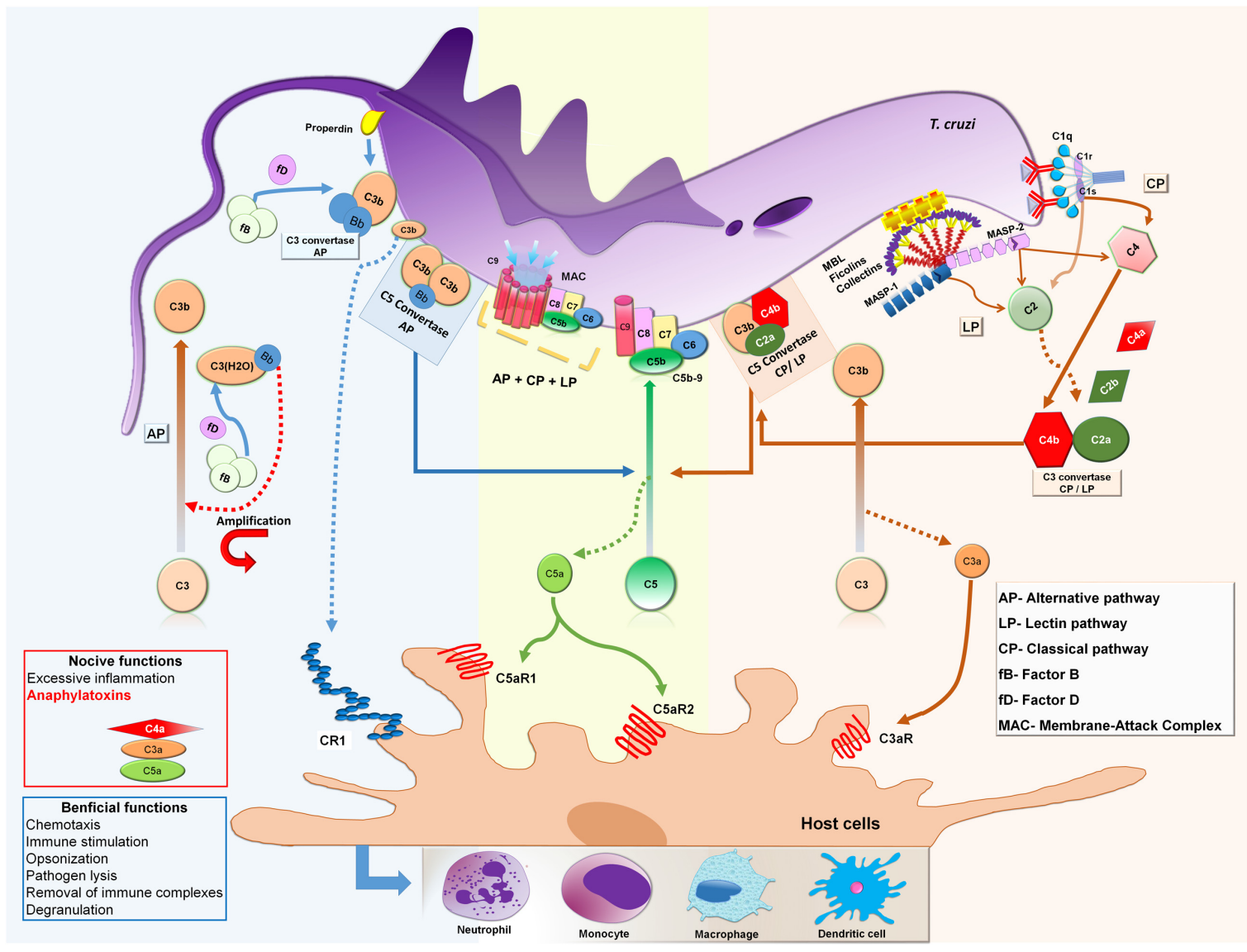

FIGURE 3 | Activation of complement system by Trypanosoma cruzi epimastigote forms. MBL and ficolins recognize and bind to glycoproteins and carbohydrates present on the T. cruzi epimastigote surface initiating the LP. This interaction leads to conformational changes in MBL and ficolins and activation of MASP- 1 followed by MASP-2 which cleavages C4 into C4a and C4b and C2 into C2a and C2b, generating C3 convertase (C4b2a). In presence of specific anti-T. cruzi antibodies, C1q molecules recognize and bind to IgM and IgG on the parasite's surface initiating the CP. Subsequently, C1q suffers conformational changes and activates $C 1$ r, which cleaves and activates $C 1$ s that subsequently cleaves $C 4$ and $C 2$ generating $C 3$ convertase (C4b2a), as in the LP convertase. When $\mathrm{C} 3 \mathrm{~b}$ binds to $\mathrm{C} 4 \mathrm{~b} 2 \mathrm{a}$ the complex forms $\mathrm{C} 4 \mathrm{~b} 2 \mathrm{aC} 3 \mathrm{~b}$, with $\mathrm{C} 5$ convertase activity. The AP is initiated by the generation of $\mathrm{C} 3(\mathrm{H} 2 \mathrm{O})$ after spontaneous hydrolysis of $\mathrm{C} 3$, or as a consequence of loop amplification triggered during LP and CP activation,. Since FB binds to $\mathrm{C} 3(\mathrm{H} 2 \mathrm{O})$, FB can be cleaved by FD in Ba and Bb. The Bb fragment remains bound to $\mathrm{C} 3(\mathrm{H} 2 \mathrm{O})$ forming the first $\mathrm{C} 3$ convertase of $\mathrm{AP}(\mathrm{C} 3(\mathrm{H} 2 \mathrm{O}) \mathrm{Bb})$, which cleaves $\mathrm{C} 3$ into $\mathrm{C} 3 \mathrm{a}$ and $\mathrm{C} 3 \mathrm{~b}$. C3b also has a binding site for $\mathrm{FB}$, allowing cleavage by FD, resulting in the second $\mathrm{C} 3$ convertase of AP, C3bBb. Additional C3b molecules are able to bind to the C3bBb complex to form C3bBb3bn which exerts C5 convertase activity. Both C5 convertases, LP/CL and AP, cleave the C5 component into C5a and C5b. Newly formed C5b reacts with C6 to form the stable C5b6 complex that recruits $\mathrm{C} 7$ resulting in a hydrophobic complex that targets the membrane (mC5b-7). Membrane insertion is initiated upon binding of C8 (C5b-8) and 12-18 copies of C9 polymerize to form the membrane attack complex (MAC) that induces lysis of target membranes. In addition, as a product of all pathways being activated, the small fragments $\mathrm{C} 4 \mathrm{a}, \mathrm{C} 3 \mathrm{a}$, and $\mathrm{C} 5 \mathrm{a}$ are formed, which are important anaphylatoxins, attracting and activating inflammatory cells to the activation site, such as neutrophils, monocytes, macrophages, and dendritic cells.

molecules on the trypomastigote's surface, such as T. cruzi calreticulin (TcCRT) (Ferreira et al., 2004a; Valck et al., 2010; Sosoniuk et al., 2014), T. cruzi complement regulatory protein (TcCRP) or Gp160 (Norris et al., 1989; Norris and Schrimpf, 1994), T. cruzi complement C2 receptor inhibitor trispanning (TcCRIT) (Cestari et al., 2008), gp58/68 (Fischer et al., 1988) and T-DAF (Tambourgi et al., 1993). In addition, it has been shown that $T$. cruzi metacyclic trypomastigote forms induce membranederived vesicles (microvesicles) from host cells, which interact with C3 convertase, resulting in inhibition of complement activation and increased parasite survival, as well as eukaryotic cell invasion (Cestari et al., 2012). Moreover, it has been reported that microvesicles, derived from the host cell membrane and also secreted by T. cruzi, can fuse thereby increasing host cell invasion (Ramirez et al., 2016) (Table 1). The molecules and microvesicles involved in T. cruzi evasion from the complement system will be covered in more detail (Figure 4).

\section{T. cruzi Calreticulin (TcCRT)}

Trypanosoma cruzi calreticulin (TcCRT) is a $45 \mathrm{kDa}$ calciumbinding protein that is primarily expressed in the ER of infective trypomastigotes. Upon infection, TcCRT is translocated from the RE to the emerging area of the flagellum on the plasma membrane surface (Ferreira et al., 2004a,b; González et al., 2015). Interestingly, this area has been shown to be the initial contact with the host plasma membrane (González et al., 2015). 
TABLE 1 | Characteristics of the molecules involved in the evasion of Trypanosoma cruzi from the complement system.

\begin{tabular}{|c|c|c|c|}
\hline Parasite molecule & Complement component & Complement pathway affected & Reference \\
\hline \multirow[t]{3}{*}{ TCCRT } & Binds to MBL collagen-like domain & Lectin pathway & Ferreira et al., 2004b \\
\hline & $\begin{array}{l}\text { Binds to Ficolin-2 collagen-like } \\
\text { domain }\end{array}$ & Lectin pathway & Sosoniuk et al., 2014 \\
\hline & $\begin{array}{l}\text { Interacts with C1q collagen-like } \\
\text { domain }\end{array}$ & Classical pathway & $\begin{array}{l}\text { Ferreira et al., 2004b; Valck et al., } \\
2010\end{array}$ \\
\hline T-DAF & $\begin{array}{l}\text { Binds to } \mathrm{C} 3 \mathrm{~b} \text { and } \mathrm{C} 4 \mathrm{~b} \text { accelerating } \\
\text { the dissociation of } \mathrm{C} 3 \text { convertase }\end{array}$ & $\begin{array}{l}\text { Alternative, classical, andlectin } \\
\text { (probably) pathways }\end{array}$ & $\begin{array}{l}\text { Joiner et al., 1988; Rimoldi et al., } \\
\text { 1988; Tambourgi et al., } 1993\end{array}$ \\
\hline TcCRP/Gp160 & $\begin{array}{l}\text { Binds to C3b and C4b preventing } \\
\text { assembly of C3 convertase }\end{array}$ & $\begin{array}{l}\text { Alternative and classical Lectin } \\
\text { (probably) pathways }\end{array}$ & $\begin{array}{l}\text { Norris et al., 1991, 1989; Norris } \\
\text { and Schrimpf, 1994; Norris, } 1998\end{array}$ \\
\hline TcCRIT & $\begin{array}{l}\text { Binds to } \mathrm{C} 2 \text { and prevent its } \\
\text { cleavage by } \mathrm{C} 1 \mathrm{~s} \text { and MASP2 }\end{array}$ & Classical and lectin pathways & Cestari et al., 2008, 2009 \\
\hline gp58/68 & $\begin{array}{l}\text { Interacts with Factor B blocking its } \\
\text { binding to } \mathrm{C} 3 \mathrm{~b}\end{array}$ & Alternative pathway & Fischer et al., 1988 \\
\hline $\begin{array}{l}\text { T. cruzi-induced membrane-derived } \\
\text { vesicles from host cells or } \\
\text { microvesicle (MV) }\end{array}$ & $\begin{array}{l}\text { Binds to } \mathrm{C} 3 \text { convertase }(\mathrm{C} 4 \mathrm{~b} 2 \mathrm{a}) \text { on } \\
\text { the T. cruzi surface, thereby } \\
\text { inhibiting } \mathrm{C} 3 \text { cleavage }\end{array}$ & Classical and lectin pathway & $\begin{array}{l}\text { Cestari et al., 2012; Ramirez et al., } \\
2016\end{array}$ \\
\hline
\end{tabular}

TcCRT expressed on the T. cruzi trypomastigote's surface is able to bind to host PRMs, similar to C1q, MBL (Ferreira et al., 2004b; Ramírez et al., 2011) and ficolins (Sosoniuk et al., 2014) interfering in the activation of the CP and LP. TcCRT also likely enhances the rate of the internalization of T. cruzi trypomastigotes by host cells (Ramírez et al., 2011, 2012).

Trypanosoma cruzi calreticulin was initially named Tc45 and described as a polypeptide present in lysates of epimastigotes and trypomastigotes. It was revealed to have an immunogenic role in the induction of specific antibodies in T. cruzi-infected mice (Ramos et al., 1991) and in human CD (Aguillón et al., 1997). Tc45 was subsequently characterized as T. cruzi calreticulin (TcCRT) as gene sequencing showed homology with calreticulin genes of other species (Aguillón et al., 2000). Later, TcCRT was found to exhibit a high homology with HuCRT, a multifunctional $46 \mathrm{kDa}$ protein present predominantly in the ER and subcellular compartments, as well as in the plasma membrane (Ferreira et al., 2004a). Extracellular HuCRT has been reported to contribute to cell adhesion to the extracellular matrix and to facilitate the uptake of apoptotic and cancerous cells by phagocytes (Lu et al., 2015). The molecule may act as a receptor for the collagenlike domain of $\mathrm{Clq}$ and $\mathrm{MBL}$, promoting phagocytosis through C1qR (Stuart et al., 1997). In fact, the role of C1q in the invasion of mononuclear phagocytes and fibroblasts by T. cruzi trypomastigotes has previously been demonstrated (Rimoldi et al., 1989). This parasite-derived molecule was later identified in infective trypomastigotes as TcCRT (Ferreira et al., 2004b) and its activity is considered one of the strategies that mediates T. cruzi uptake by mammalian phagocytic cells, mimicking the process of apoptotic cells ingestion (Ramírez et al., 2011).

In the early stages of infection, TcCRT is able to bind to the carbohydrate recognition domain of $\mathrm{MBL}$ resulting in abrogation of interaction with its natural ligands and the collagen domain of Ficolin-2, preventing $\mathrm{C} 4$ activation and impairing further activation of the LP (Ferreira et al., 2004b; Sosoniuk et al., 2014). This property however, is not shared by Ficolin-3 (Sosoniuk et al., 2014). During the late stages of T. cruzi infection the CP can be activated in the presence of specific T. cruzi antibodies, as mentioned earlier. Ferreira et al. (2004b) have demonstrated using hemolytic assays that recombinant TcCRT binds to $\mathrm{C} 1 \mathrm{q}$ collagenous tails, impairing the activation of the CP. Subsequent studies showed that TcCRT competes with the $(\mathrm{C} 1 \mathrm{r}-\mathrm{C} 1 \mathrm{~s})_{2}$ tetrameric complex for binding in the collagenous $\mathrm{C} 1 \mathrm{q}$ tails and interferes in the capacity of $\mathrm{C} 1$ s to activate $\mathrm{C} 4$ in a calcium-independent manner (Valck et al., 2010). In summary, TcCRT has been shown to be involved in the internalization of T. cruzi into mammalian cells, which increases infectivity. It is also known to be an important regulator of both the LP and CP.

\section{Trypomastigote Decay-Accelerating Factor (T-DAF)}

The T-DAF is an $87-93-\mathrm{kDa}$ glycoprotein present on the surface of metacyclic and tissue-culture-derived trypomastigote forms of T. cruzi that mimics the activity of the complement regulatory protein DAF (Tambourgi et al., 1993). T-DAF regulates the activation of the AP, CP, and probably LP, by interfering in the assembly of $\mathrm{C} 3$ convertases.

During T. cruzi infection, the three complement pathways are activated culminating with the formation of $\mathrm{C} 3$ convertase that cleaves the central component C3. The presence of molecules modulating the $\mathrm{C} 3$ convertase of the $\mathrm{CP}$ in trypomastigote but not epimastigote forms of $T$. cruzi surface was first described by Kipnis et al. (1986). It was subsequently demonstrated in a supernatant culture of trypomastigotes that these modulator molecules ranged between 86 and $155 \mathrm{kDa}$ in size, that were enriched for proteins of $86-98 \mathrm{kDa}$ absent in epimastigotes. They were shown to accelerate the decay of both the AP and CP C3 convertases in vitro by interfering in the binding of factor $\mathrm{B}$ with $\mathrm{C} 3 \mathrm{~b}$, or in the formation of $\mathrm{C} 4 \mathrm{~b} 2 \mathrm{a}$, respectively. Because of the similar behavior to human complement regulatory DAF the authors called these modulators as analogous to DAF (Rimoldi et al., 1988). In the same year Joiner et al. (1988) characterized biochemically an $87-93 \mathrm{kDa}$ factor produced by $T$. cruzi 


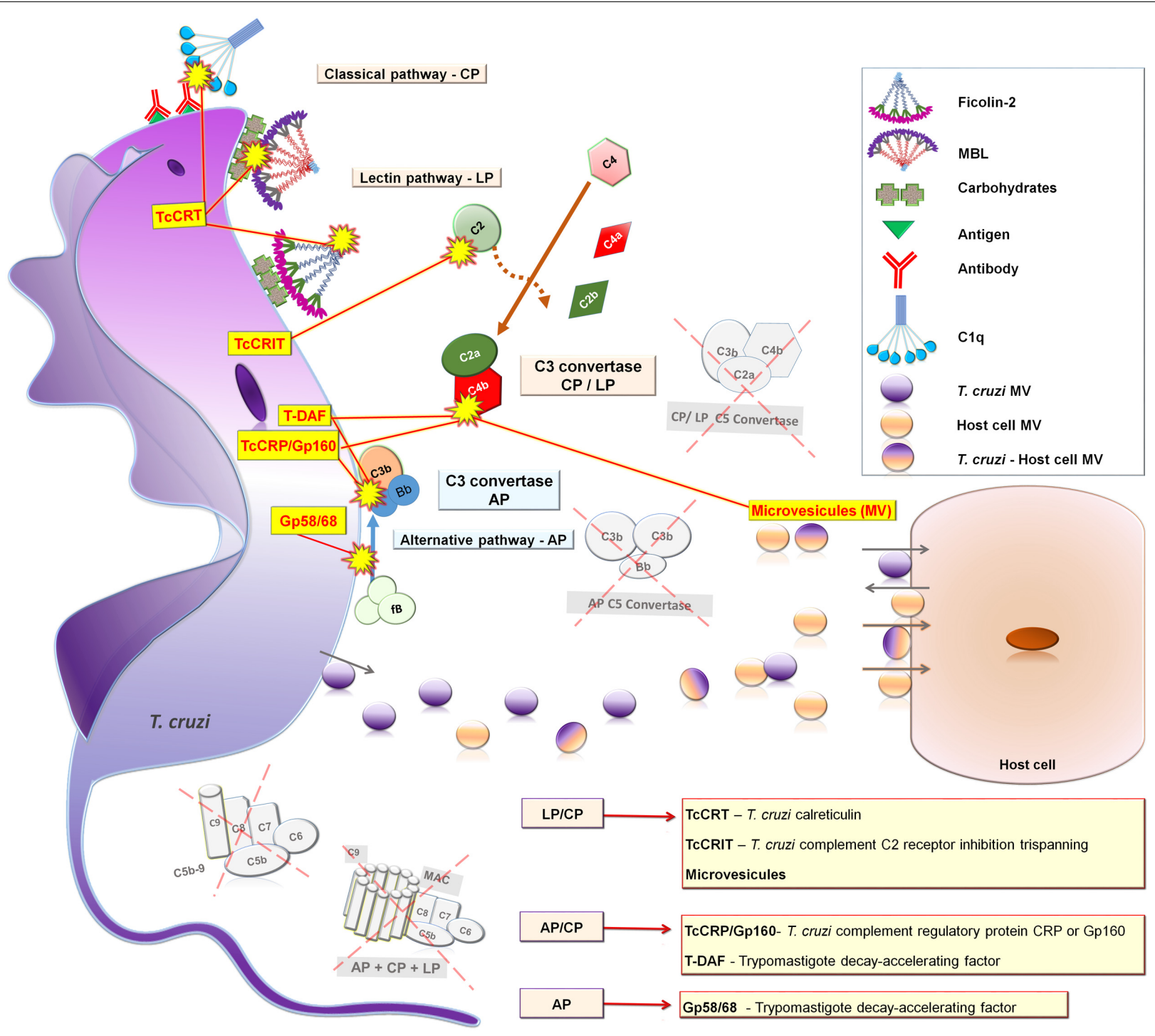

FIGURE 4 | Complement evasion by strategies of $\boldsymbol{T}$. cruzi trypomastigotes forms. TCCRT blocks CP and LP binding to C1q, MBL and Ficolin-2; T-DAF and Gp160/TcCRP block AP and CP C3 convertase assembly; TcCRIT blocks CP and LP binding to C2; gp58/68 blocks AP C3 convertase binding to factor B; and MV inhibit CP and LP C3 convertase assembly. AP, Alternative pathway; LP, Lectin pathway; and CP, Classical pathway.

trypomastigote forms responsible for accelerating the decay of C3 convertases, which appeared to be an immunogenic glycoprotein immunoprecipitated from sera of patients chronically infected with T. cruzi. Later, Tambourgi et al. (1993) called this molecule analogous to DAF as T-DAF owing to its ability in inhibiting complement activation in a manner functionally similar to mammalian DAF. In addition, polyclonal and monoclonal antibodies against T-DAF were shown to inhibit T-DAF activity in vitro, validating its functional role (Tambourgi et al., 1993). The authors also showed that T-DAF shared 40\% similarity with a portion of the DNA coding region for human DAF, and that anti-T-DAF-specific antibodies were present in up to $96 \%$ of patients with both acute and chronic CD (Tambourgi et al., 1995). In summary, T-DAF either accelerates the dissociation or assembly efficiency of C3 convertases potentially affecting the AP, CP (Tambourgi et al., 1993), and probably LP. Both soluble and surface T-DAFs are essential for the escape of T. cruzi from complement activation and lytic effects as well as the development of infection.

\section{Trypanosoma cruzi Complement Regulatory Protein (TcCRP)}

Trypanosoma cruzi complement regulatory protein (TcCRP), also called Gp160, is a $160 \mathrm{kDa}$ glycoprotein anchored into trypomastigote membranes (Norris et al., 1989) via glycosylphosphatidylinositol linkage (Norris and Schrimpf, 1994). It is also spontaneously shed in culture from trypomastigotes (Norris et al., 1991). Both membrane and soluble forms of TcCRP are able to bind to C3b and C4b inhibiting the formation of the AP and CP C3 convertases 
(Norris et al., 1991; Norris and Schrimpf, 1994), and probably LP C3 convertase as well.

Trypanosoma cruzi complement regulatory protein was initially purified and partially characterized by Norris et al. (1989) as Gp160 because of its molecular weight, and was found to be expressed in membrane extracts of both metacyclic and tissue-culture-derived T. cruzi trypomastigotes, but absent in insect epimastigotes or intracellular amastigotes. Norris and Schrimpf (1994) purified and characterized the membrane form of TcCRP having the glycolipid anchor attached which presented a molecular mass of $185 \mathrm{kDa}$. The conversion of the 185$\mathrm{kDa}$ membrane form to the $160-\mathrm{kDa}$ form was suggested to be the result of cleavage by endogenous phospholipase C. Both soluble $(160 \mathrm{kDa})$ and membrane TcCRP forms $(185 \mathrm{kDa})$ are able to bind $\mathrm{C} 3 \mathrm{~b}$ and $\mathrm{C} 4 \mathrm{~b}$ preventing the assembly of proteolytically active $\mathrm{C} 3$ convertase inhibiting both $\mathrm{AP}$ and $\mathrm{CP}$ activation (Norris et al., 1991; Norris and Schrimpf, 1994). It was then demonstrated that the TCCRP had similar activity to human CRP and DAF, being considered a member of the $\mathrm{C} 3 / \mathrm{C} 4$ binding family of complement regulatory proteins, which provided infectious trypomastigotes another mean of evading the harmful effects of complement (Norris et al., 1991). Since TcCRP binds C4b, LP activation could be also affected at the same level. Moreover, anti-TcCRP lytic antibodies were present in the sera of $T$. cruzi-infected patients. Interesting, in the presence of antiTcCRP antibodies the interaction between TcCRP and C3b was blocked allowing the AP C3 convertase assembly and parasite lysis (Norris et al., 1991).

Norris (1996) demonstrated that following the binding to C3b, TcCRP was released from the T. cruzi trypomastigote membrane by proteolytic cleavage, and these findings represented a new alternative mechanism of $T$. cruzi in evading complement activation. Interestingly, epimastigote forms transfected with a cDNA encoding full-length recombinant TcCRP were protected from complement-mediated lysis, confirming the role of TcCRP as a complement resistance factor of $T$. cruzi trypomastigotes (Norris et al., 1997; Norris, 1998). Recently, Henrique et al. (2016) demonstrated that surface expression of TcCRP differs among parasite strains, with a tendency of higher expression levels in the most virulent T. cruzi strains. In summary, TcCRP is directly involved in the evasion of T. cruzi from complement lysis by binding to $\mathrm{C} 3 \mathrm{~b}$ and $\mathrm{C} 4 \mathrm{~b}$ and consequently inhibiting both the $\mathrm{AP}$, $\mathrm{CP}$, and probably LP.

\section{T. cruzi Complement C2 Receptor Inhibitor Trispanning (TcCRIT)}

Trypanosoma cruzi complement C2 receptor inhibitor trispanning (TcCRIT) is a $32 \mathrm{kDa}$ transmembrane protein that presents a sequence homology with the $\mathrm{C} 4$ beta-chain, the binding site of $\mathrm{C} 2$. Thus, TcCRIT inhibits the cleavage of $\mathrm{C} 2$ by $\mathrm{C} 1 \mathrm{~s}$ or MASP-2 and consequently prevents C3 convertase formation by competing with C4 (Inal, 1999; Inal and Schifferli, 2002; Cestari et al., 2012). TcCRIT is mainly expressed in complement resistant trypomastigote forms of T. cruzi regulating the activation of both the CP and LP (Inal, 1999; Inal et al., 2005).
The complement C2 receptor inhibitor trispanning (CRIT) was first described in the tegument of Schistosoma haematobium and subsequently S. mansoni (Inal, 1999; Inal and Sim, 2000) as a phosphorylated tyrosine molecule named TOR that inhibited $\mathrm{C} 2$ cleavage by $\mathrm{C} 1 \mathrm{~s}$ inhibiting the $\mathrm{CP}$ activation. It was then characterized as a novel complement regulator, and named CRIT (Inal and Sim, 2000). S. haematobium TOR (Sh-TOR) protein sequencing showed a long cytoplasmic tail with several consensus phosphorylation sites for enzymes, such as tyrosine kinases, characteristically associated with membrane receptors (Inal, 1999). Later, it was demonstrated that the Sh-TOR synthetic peptide pre-incubated with $\mathrm{C} 2$ inhibited the $\mathrm{CP}$ activation both in vitro (Inal and Schifferli, 2002) and in vivo (Inal et al., 2003) by competing with $\mathrm{C} 4 \mathrm{~b}$ (which presents some sequence identity to the first extracellular domain of Sh-TOR) (Inal and Sim, 2000). CRIT is highly conserved in Schistosoma species, T. cruzi strains, and mammals (Inal, 1999, 2005). Interestingly, both the Trypanosoma parasite and its human host share a receptor for C2, with a complement regulatory function (Inal et al., 2005).

Complement C2 receptor inhibitor trispanning protein was later shown to be expressed in the infective stage of T. cruzi preventing the lytic activity of NHS. In addition, overexpression of TcCRIT in transgenic epimastigotes increased the resistance to complement-mediated killing in the presence of nonimmune NHS, blocking both the CP and LP. However, when epimastigotes were treated with exogenous $\mathrm{C} 2$ the complement activity was restored (Cestari et al., 2008). Although metacyclic trypomastigotes and epimastigotes differ regarding complement resistance, MBL, Ficolin-2 and Ficolin-3 are able to bind to glycosylated proteins on the surface of both parasites forms. However, only metacyclic trypomastigotes were shown to resist complement killing due to high expression levels of TcCRIT. TcCRIT circumvent LP activation through binding to C2, inhibiting its cleavage by MASP- 2 and C3 convertase formation (Cestari et al., 2009). In summary, TcCRIT interferes in the activation of the LP and $\mathrm{CP}$ by binding to $\mathrm{C} 2$ and preventing its cleavage by the serine proteases $\mathrm{C} 1 \mathrm{~s}$ and MASP2, thereby evading both initial branches of complement activation. This leads to resistance against complement-mediated cell lysis, allowing T. cruzi survival and cell invasion.

\section{T. cruzi Complement Regulatory gp58/68}

The T. cruzi complement regulatory gp58/68 is a glycoprotein of an apparent molecular weight of $58 \mathrm{kDa}$ (non-reduced) and $68 \mathrm{kDa}$ (reduced) (Fischer et al., 1988) that is expressed on the parasite surface or can be released by trypomastigotes in culture (Ouaissi et al., 1988; Velge et al., 1988). It is part of the T. cruzi fibronectin/collagen receptor which consists of two molecules of $80-85 \mathrm{kDa}$ and $58-68 \mathrm{kDa}$ with an important role in the attachment of trypomastigote forms to mammalian cells (Ouaissi et al., 1984, 1986; Velge et al., 1988). Gp58/68 acts as a T. cruzi complement regulatory protein shown to inhibit the formation of cell-bound and fluid-phase AP C3 convertases (Fischer et al., 1988).

Gp58/68 was first identified in studies on the biological function of T. cruzi fibronectin receptors (TcFnR) by Ouaissi et al. (1984). Human fibronectin purified from blood were 
shown to bind specifically to $T$. cruzi trypomastigotes and to be involved in cell-parasite interaction. Anti-fibronectin antibodies were able to eradicate in vitro fibroblast infection by T. cruzi trypomastigotes (Ouaissi et al., 1984). The isolation and functional characterization of TcFnR were later achieved using immunoprecipitation assays, which identified the $85 \mathrm{kDa}$ protein. Both affinity-purified TcFnR and anti-TcFnR antibodies exerted an inhibitory effect in the infection of fibroblasts by T. cruzi trypomastigotes in culture (Ouaissi et al., 1986). Subsequent studies characterized the other part of the fibronectin/collagen receptor, the collagen receptor, and showed that the same T. cruzi receptor binds to the host fibronectin and/or collagen, and that both the $80-85 \mathrm{kDa}$ and $58 / 68 \mathrm{kDa}$ glycoproteins are part of the same receptor (Velge et al., 1988). In the same year, the gp58/68 was purified by affinity chromatography from lysate of both culture and peripheral blood T. cruzi trypomastigotes and named according to its molecular weight (Fischer et al., 1988). This T. cruzi glycoprotein was able to inhibit the formation of cell-bound AP C3 convertase by preventing the initial association of $\mathrm{FB}$ with surface fixed $\mathrm{C} 3 \mathrm{~b}$ in a dose dependent manner. Moreover, gp58/68 was also shown to restrict the formation of fluid-phase AP C3 convertase by the consumption of fluidphase FB (Fischer et al., 1988). In summary, gp58/68 is part of a fibronectin/collagen receptor of $T$. cruzi that has an important role in the interaction of $T$. cruzi with mammalian cells and confers the parasite's ability to evade AP complement activation by inhibiting $\mathrm{FB} / \mathrm{C} 3 \mathrm{~b}$ interaction.

\section{Host and T. cruzi Microvesicles}

Microvesicles (MVs) are 100-1000 nm vesicles originating from the plasma membrane and are released by a large number of cells from the blood, immune system, epithelial and endothelial tissues, among others (Evans-Osses et al., 2013). MVs are involved in intercellular communication owing to their capacity to transfer proteins, lipids, and nucleic acids, thereby influencing various physiological and pathological functions of both the recipient and parent cell (Yáñez-Mó et al., 2015). MVs are known to be released by different pathogens such as bacteria, fungus, and parasites, including T. cruzi (Silveira et al., 1979; Gonçalves et al., 1991; Geiger et al., 2010), which may carry virulence factors to host cells promoting the dissemination of the pathogen (Deatheragea and Cooksona, 2012; Barteneva et al., 2013). Host mammalian cells infected with T. cruzi release MVs that interfere in CP and LP C3 convertases assembly on the parasite's surface, leading to the inhibition of its catalytic activity (Cestari et al., 2012) and consequently eliminating complement activation. Recent findings have demonstrated that interaction between $T$. cruzi trypomastigote and epimastigote forms with host cells also can induce MVs formation (Ramirez et al., 2016).

New insight into the mechanisms of complement immune evasion by T. cruzi were gain when Cestari et al. (2012) reported secretion of host MVs induced by parasitic infection. At the beginning of infection, metacyclic trypomastigotes induced the release of MVs from immune cells, such as lymphocytes, monocytes, and macrophages in a calcium-dependent process (Cestari et al., 2012). Under experimental conditions MVs were shown to strongly inhibit $\mathrm{C} 3 \mathrm{~b}$ deposition. However, $\mathrm{C} 4 \mathrm{~b}$ deposition was not significantly inhibited. These findings suggest that MVs interfered on complement at C3 level. In addition, MVs were shown to bind LP and CP C3 convertase complexes on the surface of T. cruzi inhibiting complement-mediated lysis and favoring the invasion of host cells. Moreover, C1q, Ficolin2, and Ficolin-3 were also found to bind to MVs but did not impair parasite recognition by these PRMs. It has also been shown that MVs derived from lymphocytes and monocytes carry TGF- $\beta$, an important cytokine that enhances T. cruzi cell invasion and protects the parasite against complement-mediated lysis (Cestari et al., 2012). Recently, the release of MVs derived from infective (metacyclic trypomastigote and tissue-culture-derived trypomastigote) and non-infective (epimastigote) parasites, and their interaction with host cells was demonstrated. In addition, infective and non-infective T. cruzi forms were shown to induce different levels of MV release from host cells. Moreover, the fusion of MVs derived from both host cell and parasite was demonstrated, and this phenomenon appears to facilitate contact between T. cruzi and host cell plasma membranes, and probably membrane fusion. Thus, MVs released during interaction of the parasite with host cells were able to increase host cell invasion by metacyclic trypomastigotes (Ramirez et al., 2016). In summary, interaction between T. cruzi and host cells prompt the release of MVs from both parasite and host cells and this phenomenon may contribute to evasion of CP and LP complement activation and to increase host cell infection. Thus, both host and parasite MVs probably have a potential immunomodulatory effect in the pathogenesis of T. cruzi infection.

\section{IMMUNOMODULATORY PERSPECTIVES}

Although it has been suggested that the effectiveness of the etiological treatment for $\mathrm{CD}$ is inversely proportional to the duration of $T$. cruzi infection, the success of trypanosomatid drugs in preventing clinical progression to symptomatic forms is still controversial. Considering that T. cruzi makes use of several strategies to evade the host immune system in order to establish the infection, these molecules involved in evasion mechanisms could be interesting therapeutic targets to be explored in the context of prevention and treatment of CD. Immunomodulatory therapies could be based on the use of antibodies against overexpressed T. cruzi molecules, such as TcCRT, T-DAF, TcCRP, TcCRIT, and gp58/68. For instance, T. cruzi complement regulatory proteins, such as TcCRP, T-DAF, and gp58/68, may also be targets of anti-T. cruzi lytic antibodies (as reviewed by Krautz et al., 2000) and could be used as indicators of drug efficacy in T. cruzi infection and parasite clearance, as observed by anti-TcCRP and anti-T-DAF detected in sera of CD patients (Norris et al., 1994; Tambourgi et al., 1995). In addition, the association of MBL deficiency with protection against the development and progression of chronic CD cardiomyopathy (Luz et al., 2016) highlighted a potential marker for disease progression. Moreover, an interesting therapeutic approach to control the early stage of T. cruzi infection in patients with MBL deficiency and defects in LP activation may be the restitution of MBL or other PRMs involved in complement activation. Thus, 
new investigations are needed to explore which T. cruzi evasion molecules could be potential immunotherapeutic targets that could contribute to change the pathophysiological progression of this neglected disease.

\section{CONCLUSION}

The current knowledge on complement evasion strategies used by $T$. cruzi highlights the importance of the LP, AP, and CP as crucial components in the first line of defense against this parasitic infection. However, T. cruzi infective forms are able to regulate and inhibit the complement activation early in the proteolytic cascade by expressed and/or released regulator molecules thereby circumventing complement's harmful effects. Thus, complement becomes prey of T. cruzi and has a bad day. Understanding these complement evasion strategies is crucial for the development of innovative strategies in the battle

\section{REFERENCES}

Abrahamsohn, I. A., and Dias da Silva, W. (1977). Antibody dependent cellmediated cytotoxicity against Trypanosoma cruzi. Parasitology 75, 317-323. doi: 10.1017/S0031182000051866

Aguillón, J. C., Ferreira, L., Pérez, C., Colombo, A., Molina, M. C., Wallace, A. et al. (2000). Tc45, a dimorphic Trypanosoma cruzi immunogen with variable chromosomal localization, is calreticulin. Am. J. Trop. Med. Hyg. 63, 306-312.

Aguillón, J. C., Harris, R., Molina, M. C., Colombo, A., Cortés, C., Hermosilla, T., et al. (1997). Recognition of an immunogenetically selected Trypanosoma cruzi antigen by seropositive chagasic human sera. Acta Trop. 63, 159-166. doi: 10.1016/S0001-706X(96)00619-5

Alberti, S., Marques, G., Camprubi, S., Merino, S., Tomas, J. M., Vivanco, F., et al. (1993). Clq binding and activation of the complement classical pathway by Klebsiella pneumoniae outer membrane proteins. Infect. Immun. 61, 852-860.

Barteneva, N. S., Maltsev, N., and Vorobjev, I. (2013). Microvesicles and intercellular communication in the context of parasitism. Front. Cell. Infect. Microbiol. 3:49. doi: 10.3389/fcimb.2013.00049

Beltrame, M. H., Catarino, S. J., Goeldner, I., Boldt, A. B. W., and Messias-Reason, I. J. (2015). The lectin pathway of complement and rheumatic heart disease. Front. Pediatr. 2:148. doi: 10.3389/fped.2014.00148

Bern, C., and Montgomery, S. P. (2009). An estimate of the burden of chagas disease in the united states. Clin. Infect. Dis. 49, e52-4. doi: 10.1086/605091

Bern, C., Montgomery, S. P., Herwaldt, B. L., Marin-neto, J. A., Maguire, J. H., Acquatella, H., et al. (2007). Evaluation and treatment of chagas disease in the united states a systematic review. JAMA 298, 2171-2181. doi: 10.1001/jama.298. 18.2171

Biolo, A., Ribeiro, A. L., and Clausell, N. (2010). Chagas cardiomyopathy-where do we stand after a hundred years? Prog. Cardiovasc. Dis. 52, 300-316. doi: 10.1016/j.pcad.2009.11.008

Boldt, A. B. W., Luz, P. R., and Messias-Reason, I. J. T. (2011). MASP2 haplotypes are associated with high risk of cardiomyopathy in chronic chagas disease. Clin. Immunol. 140, 63-70. doi: 10.1016/j.clim.2011.03.008

Bonney, K. M. (2014). Chagas disease in the 21st century: a public health success or an emerging threat? Parasite 21, 11. doi: 10.1051/parasite/2014012

Buscaglia, C. A., Campo, V. A., Frasch, A. C. C., and Di Noia, J. M. (2006). Trypanosoma cruzi surface mucins: host-dependent coat diversity. Nat. Rev. Microbiol. 4, 229-236. doi: 10.1038/nrmicro1351

Carroll, M. V., and Sim, R. B. (2011). Complement in health and disease. Adv. Drug Deliv. Rev. 63, 965-975. doi: 10.1016/j.addr.2011.06.005

Cestari, I., Ansa-Addo, E., Deolindo, P., Inal, J. M., and Ramirez, M. I. (2012). Trypanosoma cruzi immune evasion mediated by host cellderived microvesicles. J. Immunol. 188, 1942-1952. doi: 10.4049/jimmunol. 1102053 against $T$. cruzi infection and may pave the way for novel immunotherapies.

\section{AUTHOR CONTRIBUTIONS}

$\mathrm{KL}, \mathrm{LB}$, and AA participated in the design and writing of the manuscript. IdM-R: participated in the design, coordination, and manuscript writing. KL developed the graphic design of all figures.

\section{ACKNOWLEDGMENTS}

This work was supported by research grants from Coordenação de Aperfeiçoamento de Pessoal Superior (CAPES Edital Parasitologia Básica 32/2010) and from Conselho Nacional de Desenvolvimento Científico e Tecnológico to IM-R (CNPq).

Cestari, I., Evans-Osses, I., Schlapbach, L. J., Messias-Reason, I., and Ramirez, M. I. (2013). Mechanisms of complement lectin pathway activation and resistance by trypanosomatid parasites. Mol. Immunol. 53, 328-334. doi: 10.1016/j.molimm. 2012.08.015

Cestari, I., and Ramirez, M. I. (2010). Inefficient complement system clearance of Trypanosoma cruzi metacyclic trypomastigotes enables resistant strains to invade eukaryotic cells. PLoS ONE 5:e9721. doi: 10.1371/journal.pone.0009721

Cestari, I. S., Evans-Osses, I., Freitas, J. C., Inal, J. M., and Ramirez, M. I. (2008). Complement $\mathrm{C} 2$ receptor inhibitor trispanning confers an increased ability to resist complement-mediated lysis in Trypanosoma cruzi. J. Infect. Dis. 198, 1276-1283. doi: 10.1086/592167

Cestari, I. S., Krarup, A., Sim, R. B., Inal, J. M., and Ramirez, M. I. (2009). Role of early lectin pathway activation in the complement-mediated killing of Trypanosoma cruzi. Mol. Immunol. 47, 426-437. doi: 10.1016/j.molimm.2009. 08.030

Cochrane, C. G., and Müller-Eberhard, H. J. (1968). The derivation of two distinct anaphylatoxin activities from the third and fifth components of human complement. J. Exp. Med. 127, 371-386. doi: 10.1084/jem.127.2.371

Deatheragea, B. L., and Cooksona, B. T. (2012). Membrane vesicle release in bacteria, eukaryotes, and archaea: a conserved yet underappreciated aspect of microbial life. Infect. Immun. 80, 1948-1957. doi: 10.1128/IAI. 06014-11

Dias da Silva, W., Eisele, J. W., and Lepow, I. H. (1967). Complement as a mediator of inflammation. III. Purification of the activity with anaphylatoxin properties generated by interaction of the first four components of complement and its identification as a cleavage product of C'3. J. Exp. Med. 126, 1027-1048. doi: 10.1084/jem.126.6.1027

Dias da Silva, W., and Lepow, I. H. (1967). Complement as a mediator of inflammation. II. Biological properties of anaphylatoxin prepared with purified components of human complement. J. Exp. Med. 125, 921-946. doi: 10.1084/ jem.125.5.921

Dvorak, J. A., and Howe, C. L. (1976). The attraction of Trypanosoma cruzi to vertebrate cells In Vitro. J. Protozool. 23, 534-537. doi: 10.1126/science.294. 5546.1483

Dvorak, J. A., and Hyde, T. P. (1973). Trypanosoma cruzi: interaction with vertebrate cells in vitro. Exp. Parasitol. 34, 268-283. doi: 10.1016/0014-4894(73) 90087-8

European Centre for Disease Prevention and Control [ECDC] (2014). Assessing the Burden of Key Infectious Diseases Affecting Migrant Populations in the EU/EEA. Stockholm: European Centre for Disease Prevention and Control, doi: $10.2900 / 28792$

Evans-Osses, I., Messias-Reason, I., and Ramirez, M. I. (2013). The emerging role of complement lectin pathway in trypanosomatids: molecular bases in activation, genetic deficiencies, susceptibility to infection, and complement system-based therapeutics. Sci. World J. 2013:675898. doi: 10.1155/2013/675898 
Ferreira, V., Molina, M. C., Valck, C., Rojas, A., Aguilar, L., Ramírez, G., et al. (2004a). Role of calreticulin from parasites in its interaction with vertebrate hosts. Mol. Immunol. 40, 1279-1291. doi: 10.1016/j.molimm.2003.11.018

Ferreira, V., Valck, C., Sánchez, G., Gingras, A., Tzima, S., Molina, M. C., et al. (2004b). The classical activation pathway of the human complement system is specifically inhibited by calreticulin from Trypanosoma cruzi. J. Immunol. 172, 3042-3050. doi: 10.4049/jimmunol.172.5.3042

Fischer, E., Ouaissi, M. A., Velget, P., Cornette, J., and Kazatchkine, M. D. (1988). Gp 58/68, a prasite component that contributes to the escape of the trypomastigote form of $T$. cruzi from damage by the human alternative complement pathway. Imumunology 65, 299-303.

Flierman, R., and Daha, M. R. (2007). The clearance of apoptotic cells by complement. Immunobiology 212, 363-370. doi: 10.1016/j.imbio.2006.11.005

Frederiksen, P. D., Thiel, S., Larsen, C. B., and Jensenius, J. C. (2005). M-Ficolin, an innate immune defence molecule, binds patterns of acetyl groups and activates complement. Scand. J. Immunol. 62, 462-473. doi: 10.1111/j.1365-3083.2005. 01685.x

Geiger, A., Hirtz, C., Bécue, T., Bellard, E., Centeno, D., Gargani, D., et al. (2010). Exocytosis and protein secretion in Trypanosoma. BMC Microbiol. 10:20. doi: 10.1186/1471-2180-10-20

Gonçalves, M. F., Umezawa, E. S., Katzin, A. M., Souza, W., Alves, M. J. M., Zingales, B., et al. (1991). Trypanosoma cruzi: shedding of surface antigens as membrane vesicles. Exp. Parasitol. 72, 43-53. doi: 10.1016/0014-4894(91) 90119-H

González, A., Valck, C., Sánchez, G., Härtel, S., Mansilla, J., Ramírez, G., et al. (2015). Trypanosoma cruzi calreticulin topographical variations in parasites infecting murine macrophages. Am. J. Trop. Med. Hyg. 92, 887-897. doi: 10.4269/ajtmh.14-0497

Gout, E., Garlatti, V., Smith, D. F., Lacroix, M., Dumestre-Pérard, C., Lunardi, T., et al. (2010). Carbohydrate recognition properties of human ficolins: glycan array screening reveals the sialic acid binding specificity of M-Ficolin. J. Biol. Chem. 285, 6612-6622. doi: 10.1074/jbc.M109.065854

Henrique, P. M., Marques, T., da Silva, M. V., Nascentes, G. A. N., de Oliveira, C. F., Rodrigues, V. I., et al. (2016). Correlation between the virulence of T. cruzi strains, complement regulatory protein expression levels, and the ability to elicit lytic antibody production. Exp. Parasitol. 170, 66-72. doi: 10.1016/j.exppara. 2016.09.001

Hidron, A., Vogenthaler, N., Santos-Preciado, J. I., Rodriguez-Morales, A. J., Franco-Paredes, C., and Rassi, A. (2010). Cardiac involvement with parasitic infections. Clin. Microbiol. Rev. 23, 324-349. doi: 10.1128/CMR. 00054-09

Iida, K., Whitlow, M. B., and Nussenzweig, V. (1989). Amastigotes of Trypanosoma cruzi escape destruction by the terminal in the absence of antibody, the alternative pathway of the complement system can function as a first barrier in preventing infection. however, certain microorganisms have developed mec. Trop. Med. 169, 881-891.

Inal, J. M. (1999). Schistosoma TOR (trispanning Orphan Receptor), a novel, antigenic surface receptor of the blood-dwelling, schistosoma parasite. Biochim. Biophys. Acta 1445, 283-298. doi: 10.1016/S0167-4781(99)00051-2

Inal, J. M. (2005). Complement C2 receptor inhibitor trispanning: from man to schistosome. Springer Semin. Immunopathol. 27, 320-331. doi: 10.1007/s00281005-0009-9

Inal, J. M., Hui, K. M., Miot, C., Lange, S., Ramirez, M. I., Schneider, B., et al. (2005). Complement C2 receptor inhibitor trispanning: a novel human complement inhibitory receptor. J. Immunol. 174, 356-366. doi: 10.4049/jimmunol.174.1. 356

Inal, J. M., and Schifferli, J. A. (2002). Complement C2 receptor inhibitor trispanning and the Beta-chain of $\mathrm{C} 4$ share a binding site for complement $\mathrm{C} 2$. J. Immunol. 168, 5213-5221. doi: 10.4049/jimmunol.168.10.5213

Inal, J. M., Schneider, B., Armanini, M., and Schifferli, J. A. (2003). A peptide derived from the parasite receptor, complement $\mathrm{C} 2$ receptor inhibitor trispanning, suppresses immune complex-mediated inflammation in mice. J. Immunol. 170, 4310-4317. doi: 10.4049/jimmunol.170.8.4310

Inal, J. M., and Sim, R. B. (2000). A schistosoma protein, Sh-TOR, is a novel inhibitor of complement which binds human C2. FEBS Lett. 470, 131-134. doi: 10.1016/S0014-5793(00)01304-1

Joiner, K., Sher, A., Gaither, T., and Hammer, C. (1986). Evasion of alternative complement pathway by Trypanosoma cruzi results from inefficient binding of
factor-B. Proc. Natl. Acad. Sci. U.S.A. 83, 6593-6597. doi: 10.1073/pnas.83.17. 6593

Joiner, K. A., DaSilva, W. D., Rimoldi, M. T., Hammer, C. H., Sher, A., and Kipnis, T. L. (1988). Biochemical characterization of a factor produced by trypomastigotes of Trypanosoma cruzi that accelerates the decay of complement C3 convertases. J. Biol. Chem. 263, 11327-11335.

Keshi, H., Sakamoto, T., Kawai, T., Ohtani, K., Katoh, T., Jang, S., et al. (2006). Identification and characterization of a novel human collectin CL-K1. Microbiol. Immunol. 50, 1001-1013. doi: 10.1111/j.1348-0421.2006. tb03868.x

Kipnis, T. L., Krettli, A. U., and Da Silva, W. D. (1985). Transformation of trypomastigote forms of Trypanosoma cruzi into activators of alternative complement pathway by immune IgG fragments. Scand. J. Immunol. 22, 217-226. doi: 10.1111/j.1365-3083.1985.tb01874.x

Kipnis, T. L., Tambourgi, D. V., Sucupira, M., and da Silva, W. D. (1986). Effect of Trypanosoma cruzi membrane components on the formation of the classical pathway C3 convertase. Braz. J. Med. Biol. 19, 271-278.

Kishore, U., Ghai, R., Greenhough, T. J., Shrive, A. K., Bonifati, D. M., Gadjeva, M. G., et al. (2004). Structural and functional anatomy of the globular domain of complement protein C1q. Immunol. Lett. 95, 1-27. doi: 10.1038/jid.2014.371

Kjaer, T. R., Thiel, S., and Andersen, G. R. (2013). Toward a structure-based comprehension of the lectin pathway of complement. Mol. Immunol. 56, 413-422. doi: 10.1016/j.molimm.2013.05.007

Kondos, S. C., Hatfaludi, T., Voskoboinik, I., Trapani, J. A., Law, R. H. P., Whisstock, J. C., et al. (2010). The structure and function of mammalian membrane-attack complex/perforin-like proteins. Tissue Antigens 76, 341-351. doi: 10.1111/j.1399-0039.2010.01566.x

Krautz, G. M., Kissinger, J. C., and Krettli, A. U. (2000). The targets of the lytic antibody response against Trypanosoma cruzi. Parasitol. Today 16, 31-34. doi: 10.1016/S0169-4758(99)01581-1

Lambris, J. D., Ricklin, D., and Geisbrecht, B. V. (2008). Complement evasion by human pathogens. Nat. Rev. Microbiol. 6, 132-142. doi: 10.1038/nrmicro1824

Lederkremer, R., and Bertello, L. (2001). Glycoinositolphospholipids, free and as anchors of proteins, in Trypanosoma cruzi. Curr. Pharm. Des. 7, 1165-1179. doi: $10.2174 / 1381612013397519$

Lee, B. Y., Bacon, K. M., Bottazzi, M. E., and Hotez, P. J. (2013). Global economic burden of chagas disease: a computational simulation model. Lancet Infect. Dis. 13, 342-348. doi: 10.1016/S1473-3099(13)70002-1

Levine, N. D., Corliss, J. O., Cox, F. E. G., Deroux, G., Grain, J., Honigberg, B. M., et al. (1980). A newly revised classification of the protozoa. J. Protozool. 27, 37-58. doi: 10.1111/j.1550-7408.1980.tb04228.x

Lidani, K. C. F., Beltrame, M. H., Luz, P. R., Sandri, T. L., Nisihara, R. M., and Messias-Reason, I. J. (2015). Is pentraxin 3 a cardiovascular marker in patients with chronic chagas disease? Int. J. Cardiol. 190, 233-235. doi: 10.1016/j.ijcard. 2015.04.106

Lörincz, Z., Gál, P., Dobó, J., Cseh, S., Szilágyi, K., Ambrus, G., et al. (2000). The cleavage of two C1s subunits by a single active C1r reveals substantial flexibility of the $\mathrm{C} 1 \mathrm{~s}-\mathrm{C} 1 \mathrm{r}-\mathrm{C} 1 \mathrm{r}-\mathrm{C} 1 \mathrm{~s}$ tetramer in the $\mathrm{C} 1$ complex. J. Immunol. 165, 2048-2051. doi: 10.4049/jimmunol.165.4.2048

Lu, Y. C., Weng, W. C., and Lee, H. (2015). Functional roles of calreticulin in cancer biology. BioMed Res. Int. 2015, 9. doi: 10.1155/2015/526524

Luz, P. R., Miyazaki, M. I., Neto, N. C., Padeski, M. C., Barros, A. C. M., Boldt, A. B. W., et al. (2016). Genetically determined MBL deficiency is associated with protection against chronic cardiomyopathy in chagas disease. PLoS Negl. Trop. Dis. 10:e0004257. doi: 10.1371/journal.pntd.0004257

Luz, P. R., Velavan, T. P., Kremsner, P. G., and Messias-Reason, I. J. T. (2013). Association of IP-10 and PDGF-BB levels with clinical forms of chronic chagas disease. Int. J. Cardiol. 169, e53-e55. doi: 10.1016/j.ijcard.2013. 08.110

Malik, L. H., Singh, G. D., and Amsterdam, E. A. (2015). The epidemiology, clinical manifestations, and management of chagas heart disease. Clin. Cardiol. 38, 565-569. doi: 10.1002/clc.22421

Merle, N. S., Church, S. E., Fremeaux-Bacchi, V., and Roumenina, L. T. (2015). Complement system part I-molecular mechanisms of activation and regulation. Front. Immunol. 6:262. doi: 10.3389/fimmu.2015.00262

Miller, G. W., and Nussenzweig, V. (1974). Complement as a regulator of interactions between immune complexes and cell membranes. J. Immunol. 113, 464-469. 
Navarro, M., Navaza, B., Guionnet, A., and López-Vélez, R. (2012). Chagas disease in spain: need for further public health measures. PLoS Negl. Trop. Dis. 6:e1962. doi: 10.1371/journal.pntd.0001962

Nogueira, N., Bianco, C., and Cohn, Z. (1975). Studies on the selective lysis and purification of Trypanosoma cruzi. J. Exp. Med. 142, 224-229. doi: 10.1084/jem. 142.1.224

Nogueira, N. P., Saraiva, F. M. S., Sultano, P. E., Cunha, P. R. B. B., Laranja, G. A. T., Justo, G. A., et al. (2015). Proliferation and differentiation of Trypanosoma cruzi inside its vector have a new trigger: redox status. PLoS ONE 10:e0116712. doi: 10.1371 /journal.pone.0116712

Noris, M., and Remuzzi, G. (2013). Overview of complement activation and regulation. Semin. Nephrol. 33, 479-492. doi: 10.1016/j.semnephrol.2013.08.001

Norris, K. A. (1996). Ligand-binding renders the $160 \mathrm{kDa}$ Trypanosoma cruzi complement regulatory protein susceptible to proteolytic cleavage. Microb. Pathog. 21, 235-248. doi: 10.1006/mpat.1996.0058

Norris, K. A. (1998). Stable transfection of Trypanosoma cruzi epimastigotes with the trypomastigote-specific complement regulatory protein cDNA confers complement resistance. Infect. Immun. 66, 2460-2465.

Norris, K. A., Bradt, B., Cooper, N. R., and So, M. (1991). Characterization of a Trypanosoma cruzi C3 binding protein with functional and genetic similarities to the human complement regulatory protein, decay-accelerating factor. J. Immunol. 147, 2240-2247.

Norris, K. A., Galvao, L. M. C., Schrimpf, J. E., Cancado, J. R., and Krettli, A. U. (1994). Humoral immune response to the Trypanosoma cruzi complement regulatory protein as an indicator of parasitologic clearance in human chagas'. Dis. Infect. Immun. 62, 4072-4074.

Norris, K. A., Harth, G., and So, M. (1989). Purification of a Trypanosoma cruzi membrane glycoprotein which elicits lytic antibodies. Infect. Immun. 57, 2372-2377.

Norris, K. A., and Schrimpf, J. E. (1994). Biochemical analysis of the membrane and soluble forms of the complement regulatory protein of Trypanosoma cruzi. Infect. Immun. 62, 236-243.

Norris, K. A., Schrimpf, J. E., and Szabo, M. J. (1997). Identification of the gene family encoding the 160-Kilodalton Trypanosoma cruzi complement regulatory protein. Infect. Immun. 65, 349-357.

Nunes, M. C. P., Dones, W., Morillo, C. A., Encina, J. J., and Ribeiro, A. L. (2013). Chagas disease: an overview of clinical and epidemiological aspects. J. Am. Coll. Cardiol. 62, 767-776. doi: 10.1016/j.jacc.2013. 05.046

Ouaissi, M. A., Afchain, D., Capron, A., and Grimaud, J. A. (1984). Fibronectin receptors on Trypanosoma cruzi trypomastigotes and their biological function. Nature 308, 380-382. doi: 10.1038/308380a0

Ouaissi, M. A., Cornette, J., and Capron, A. (1986). Identification and isolation of Trypanosoma cruzi trypomastigote cell surface protein with properties expected of a fibronectin receptor. Mol. Biochem. Parasitol. 19, 201-211. doi: 10.1016/ 0166-6851(86)90002-2

Ouaissi, M. A., Cornette, J., Taibi, A., Velge, P., and Capron, A. (1988). Major surface immunogens of Trypanosoma cruzi trypomastigotas. Mem. Inst. Oswaldo Cruz 83, 502. doi: 10.1590/S0074-02761988000 500058

Pereira, P. C. M., and Navarro, E. C. (2013). Challenges and perspectives of chagas disease: a review. J. Venom. Anim. Toxins Incl. Trop. Dis. 19:34. doi: 10.1186/ 1678-9199-19-34

Ramírez, G., Valck, C., Aguilar, L., Kemmerling, U., López-Muñoz, R., Cabrera, G., et al. (2012). Roles of Trypanosoma cruzi calreticulin in parasite-host interactions and in tumor growth. Mol. Immunol. 52, 133-140. doi: 10.1016/ j.molimm.2012.05.006

Ramírez, G., Valck, C., Molina, M. C., Ribeiro, C. H., López, N., Sánchez, G., et al. (2011). Trypanosoma cruzi calreticulin: a novel virulence factor that binds complement $\mathrm{C} 1$ on the parasite surface and promotes infectivity. Immunobiology 216, 265-273. doi: 10.1016/j.imbio.2010.04.001

Ramirez, M. I., Deolindo, P., de Messias-Reason, I. J., Arigi, E. A., Choi, H., Almeida, I. C., et al. (2016). Dynamic flux of microvesicles modulate parasitehost cell interaction of Trypanosoma cruzi in Eukaryotic Cells. Cell. Microbiol. 19:e12672. doi: $10.1111 / \mathrm{cmi} .12672$

Ramos, R., Juri, M., Ramos, A., Hoecker, G., Lavandero, S., Pena, P., et al. (1991). An immunogenetically defined and immunodominant Trypanosoma cruzi Antigen. Am. J. Trop. Med. Hyg. 44, 314-322.
Rassi, A. Jr., Rassi, S. G., and Rassi, A. (2001). Sudden death in Chagas' disease. Arq. Bras. Cardiol. 76, 86-96. doi: 10.1590/S0066-782X2001000100008

Rassi, A., and Marin-Neto, J. A. (2010). Chagas Disease. Lancet 375, 1388-1402. doi: 10.1016/S0140-6736(10)60061-X

Ricklin, D., Hajishengallis, G., Yang, K., and Lambris, J. D. (2010). Complement: a key system for immune surveillance and homeostasis. Nat. Immunol. 11, 785-797. doi: 10.1038/ni.1923

Ricklin, D., and Lambris, J. D. (2013). Complement in immune and inflammatory disorders: pathophysiological mechanisms. J. Immunol. 190, 3831-3838. doi: 10.4049/jimmunol.1203487

Ricklin, D., Reis, E. S., and Lambris, J. D. (2016). Complement in disease: a defence system turning offensive. Nat. Rev. Nephrol. 12, 383-401. doi: 10.1038/nrneph. 2016.70

Rimoldi, M. T., Sher, A., Heiny, S., Lituchy, A., Hammer, C. H., and Joiner, K. A. (1988). Developmentally regulated expression by Trypanosoma cruzi of molecules that accelerate the decay of complement C3 convertases. Proc. Natl. Acad. Sci. U.S.A. 85, 193-197. doi: 10.1073/pnas.85.1.193

Rimoldi, M. T., Tenner, A. J., Bobak, D. A., and Joiner, K. A. (1989). Complement component $\mathrm{Clq}$ enhances invasion of human mononuclear phagocytes and fibroblasts by Trypanosoma cruzi Trypomastigotes. J. Clin. Invest. 84, 19821989. doi: 10.1172/JCI114388

Sacks, D., and Sher, A. (2002). Evasion of innate immunity by parasitic protozoa. Nat. Immunol. 3, 1041-1047. doi: 10.1038/ni1102-1041

Salvatella, R., Irabedra, P., Sánchez, D., Castellanos, L. G., and Espinal, M. (2013). South-south cooperation for chagas disease. Lancet 382, 395-396. doi: 10.1016/ S0140-6736(13)61671-2

Schijman, A. G., Bisio, M., Orellana, L., Sued, L., Duffy, T., Jaramillo, A. M. M., et al. (2011). International study to evaluate PCR methods for detection of Trypanosoma cruzi DNA in blood samples from chagas disease patients. PLoS Negl. Trop. Dis. 5:e931. doi: 10.1371/journal.pntd. 0000931

Schmunis, G. A. (2007). Epidemiology of chagas disease in non-endemic countries: the role of international migration. Mem. Inst. Oswaldo Cruz 102(Suppl. 1), 75-85. doi: 10.1590/S0074-02762007005000093

Silveira, J. F., da Abrahamsohn, P. A., and Colli, W. (1979). Plasma membrane vesicles isolated from epimastigote forms of Trypanosoma cruzi. Biochim. Biophys. Acta 550, 222-232. doi: 10.1016/0005-2736(79) 90209-8

Singh, G., and Sehgal, R. (2010). Transfusion-transmitted parasitic infections. Asian J. Transfus. Sci. 4, 73. doi: 10.4103/0973-6247.67018

Sosoniuk, E., Vallejos, G., Kenawy, H., Gaboriaud, C., Thielens, N., Fujita, T., et al. (2014). Trypanosoma cruzi calreticulin inhibits the complement lectin pathway activation by direct interaction with L-ficolin. Mol. Immunol. 60, 80-85. doi: 10.1016/j.molimm.2014.03.014

Souza, W., Carvalho, T. M. U., and Barrias, E. S. (2010). Review on Trypanosoma cruzi: host cell interaction. Int. J. Cell Biol. 2010:295394. doi: 10.1155/2010/ 295394

Stanaway, J. D., and Roth, G. (2015). The burden of chagas disease estimates and challenges. Global Heart 10, 139-144. doi: 10.1016/j.gheart.2015.06.001

Stuart, G. R., Lynch, N. J., Day, A. J., Schwaeble, W. J., and Sim, R. B. (1997). The C1q and collectin binding site within C1q receptor (cell surface Calreticulin). Immunopharmacology 38, 73-80. doi: 10.1016/S0162-3109(97) 00076-3

Sugimoto, R., Yae, Y., Akaiwa, M., Kitajima, S., Shibata, Y., Sato, H., et al. (1998). Cloning and characterization of the hakata antigen, a member of the ficolin/opsonin p35 lectin family. J. Biol. Chem. 273, 20721-20727. doi: 10.1074/ jbc.273.33.20721

Tambourgi, D. V., Cavinato, R. A., De Abreu, C. M., Peres, B. A., and Kipnis, T. L. (1995). Detection of Trypanosoma-decay accelerating factor antibodies in mice and humans infected with Trypanosoma cruzi. Am. J. Trop. Med. Hyg. 52, 516-520.

Tambourgi, D. V., Kipnis, T. L., Da Silva, W. D., Joiner, K. A., Sher, A., Heath, S., et al. (1993). A partial cDNA Clone of Trypomastigote Decay-Accelerating Factor (T-DAF), a developmentally regulated complement inhibitor of Trypanosoma cruzi, has genetic and functional similarities to the human complement inhibitor DAF. Infect. Immun. 61, 3656-3663.

Valck, C., Ramírez, G., López, N., Ribeiro, C. H., Maldonado, I., Sánchez, G., et al. (2010). Molecular mechanisms involved in the inactivation of 
the first component of human complement by Trypanosoma cruzi Calreticulin. Mol. Immunol. 47, 1516-1521. doi: 10.1016/j.molimm.2010. 01.019

van Lookeren, C. M., Wiesmann, C., and Brown, E. J. (2007). Macrophage complement receptors and pathogen clearance. Cell Microbiol. 9, 2095-2102. doi: 10.1111/j.1462-5822.2007.00981.x

Velge, P., Ouaissi, M. A., Cornette, J., Afchain, D., and Capron, A. (1988). Identification and isolation of Trypanosoma cruzi trypomastigote collagenbinding proteins: possible role in cell-parasite interaction. Parasitology 97(Pt 2), 255-268. doi: 10.1017/S0031182000058467

Walport, M. J. (2001). Complement first of two parts. N. Engl. J. Med. 344, 1058-1066.

Watanabe Costa, R., Silveira, J. F., and Bahia, D. (2016). Interactions between Trypanosoma cruzi secreted proteins and host cell signaling pathways. Front. Microbiol. 7:388. doi: 10.3389/fmicb.2016. 00388

Weis, W. I., Drickamer, K., and Hendrickson, W. (1992). Structure of a C-Type mannose-binding protein complexed with an oligosaccharide. Nature 360, 127-134. doi: 10.1038/360127a0

Weitzel, T., Zulantay, I., Danquah, I., Hamann, L., Schumann, R. R., Apt, W., et al. (2012). Mannose-binding lectin and toll-like receptor polymorphisms and chagas disease in chile. Am. J. Trop. Med. Hyg. 86, 229-232. doi: 10.4269/ajtmh. 2012.11-0539

World Health Organization [WHO] (2009). Control and Prevention of Chagas Disease in Europe. Geneva: World Health Organization, 69.
World Health Organization [WHO] (2010). Working to Overcome the Global Impact of Neglected Tropical Diseases First WHO Report on Neglected Tropical Diseases. Geneva: World Health Organization.

World Health Organization [WHO] (2015). Chagas disease in latin america: an epidemiological update based on 2010 estimates. Wkly. Epidemiol. Rec. 6, 33-44. doi: 10.2147/IBPC.S70402

Yáñez-Mó, M., Siljander, P. R. M., Andreu, Z., Zavec, A. B., Borràs, F. E., Buzas, E. I., et al. (2015). Biological properties of extracellular vesicles and their physiological functions. J. Extracell. Vesicles 4:27066. doi: 10.3402/jev.v4.27066

Conflict of Interest Statement: The authors declare that the research was conducted in the absence of any commercial or financial relationships that could be construed as a potential conflict of interest.

The reviewer WDDS and handling Editor declared their shared affiliation, and the handling Editor states that the process nevertheless met the standards of a fair and objective review.

Copyright (c) 2017 Lidani, Bavia, Ambrosio and de Messias-Reason. This is an openaccess article distributed under the terms of the Creative Commons Attribution License (CC BY). The use, distribution or reproduction in other forums is permitted, provided the original author(s) or licensor are credited and that the original publication in this journal is cited, in accordance with accepted academic practice. No use, distribution or reproduction is permitted which does not comply with these terms. 